Molecular Identification of Toxigenic Cyanobacteria and Effects of Cyanotoxins on Human Renal Cell Lines by

Mapalagama Acharige Poorna Chathurani Piyathilaka

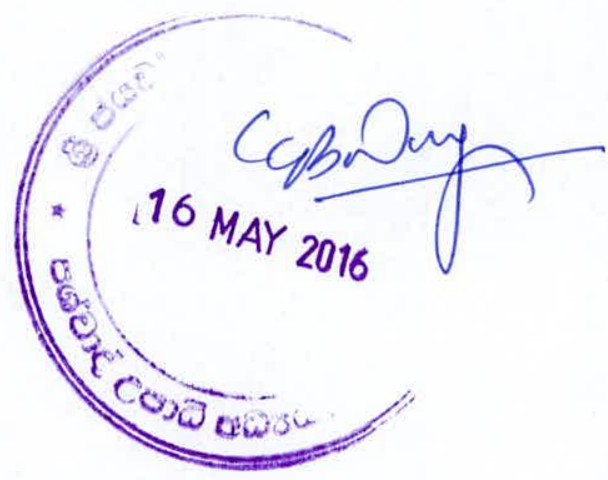

Thesis submitted to the University of Sri Jayewardenepura for the award of the Degree of Doctor of Philosophy in Zoology on 2015 


\section{Certification of the Supervisors}

"We certify that the candidate has incorporated all corrections, additions and amendments recommended by the examiners to this final version of the $\mathrm{PhD}$ thesis".

Supervisor:

Prof. Pathmalal Manage

Professor of Zoology,

Department of Zoology,

Faculty of Applied Sciences, University of Sri Jayewardenepura.

$\underset{\text { Date }}{.1 .4 .1 .0 .5 .2016 . .}$

Co-Supervisor:

Prof. Kamani H. Tennekoon

Senior Professor of Molecular Life Sciences,

Institute of Biochemistry, Molecular Biology and Biotechnology University of Colombo.

$14 . \operatorname{os} 2016 \ldots \ldots$

Date

Co-Supervisor:

Prof. Nissanka De Silva

Professor of Zoology, Department of Zoology, Faculty of Applied Sciences, University of Sri Jayewardenepura.

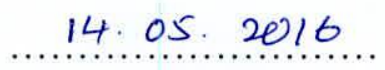

Date

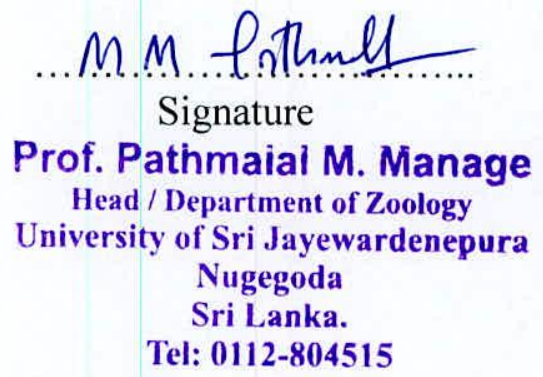




\section{Declaration of the Candidate}

"The work described in this thesis was carried out by me under the supervision of Prof. Pathmalal Manage (Supervisor), Prof. Kamani H. Tennekoon (Co-Supervisor) and Prof. Nissanka De Silva (Co-Supervisor) and a report on this has not been submitted in whole or in part to any university or any other institution for another Degree/ Diploma".

Date

\section{4. $05 \cdot 2016$}

Name of the Candidate
Signature of the $\mathrm{PhD}$ candidate

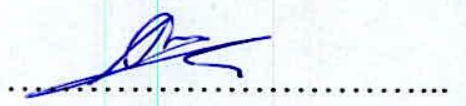




\section{Declaration of the Supervisors}

"We certify that the above statement made by the candidate is true and that this thesis is suitable for submission to the University for the purpose of evaluation".

Supervisor:

Prof. Pathmalal Manage

Professor of Zoology,

Department of Zoology,

Faculty of Applied Sciences, University of Sri Jayewardenepura.

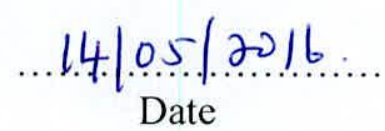

Co-Supervisor:

Prof. Kamani H. Tennekoon

Senior Professor of Molecular Life Sciences, Institute of Biochemistry, Molecular Biology and Biotechnology University of Colombo.

...14... $05.2016 \ldots \ldots$

Date

Co-Supervisor:

Prof. Nissanka De Silva

Professor of Zoology, Department of Zoology, Faculty of Applied Sciences, University of Sri Jayewardenepura.

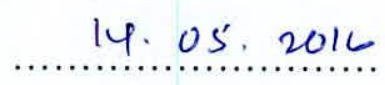

Date

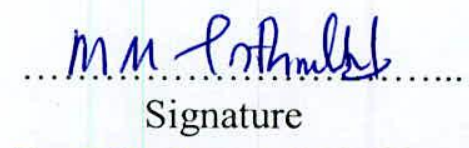

Prof. Pathmalal M. Manage

Head / Department of Zoology University of Sri Jayewardenepura

Nugegoda

Sri Lanka.

Tel: 0112-804515 
Dedication

To my darling twin daughters Vidushi and Virushi 
Certification of the Supervisor

Declaration of the Candidate

Declaration of the Supervisors

v

Dedication

vi

Table of Contents

vii

List of Figures

ix

List of Tables

xviii

List of Abbreviations

XX

Acknowledgement

XXV

Abstract

xxvii

1. Introduction

1.1 General Introduction

1.2 Cyanotoxins and their health effects

1.3 Cyanotoxin intoxication incidences

1.4 Experimental evidences for toxicity of cyanotoxins

1.5 Guidelines for cyanotoxins

1.6 Molecular detection of toxic cyanobacteria 
1.7 Microcystin biosynthesis

1.8 Phylogenetic identification of cyanobacterial strains

1.9 Mechanism of toxigenicity of microcystins

1.10 Cellular uptake of microcystins

1.11 Relationship of cyanotoxins and Chronic Renal Disease in Sri Lanka

1.12 Objectives

2. Literature Review

2.1 Origin and occurrence of Cyanobacteria

2.2 Cellular structure of Cyanobacteria

2.3 Morphology of cyanobacteria

2.4 Classification of cyanobacteria

2.5 Ecophysiology

2.6 Importance of cyanobacteria

2.7 Blooming of Cyanobacteria

2.8 Toxin producing cyanobacteria

2.9 Cyanotoxins

2.9.1 Microcystins (MCs)

2.9.2 Cylindrospermopsin (CYL)

2.10 History of intoxication due to cyanotoxins 
2.12 Screening of cyanotoxins by chemical methods

2.13 Molecular basis of Cyanotoxin production of cyanobacteria

2.14 Microcystin producing and non-producing cyanobacterial blooms

2.15 Molecular biological techniques for Identification of toxic and non-toxic strains of Cyanobacteria

2.16 Cellular Uptake of Microcystins

2.17 Toxic effects of cyanotoxins

2.18 MC and apoptosis

2.19 Bioaccumulation of cyanotoxins

2.20.1 CKDu case definition

2.21 Removal of Microcystins and other cyanotoxins from drinking water

3.2 Water quality analysis

3.2.1 Chemical analysis

3.2.2 Identification and enumeration of cyanobacteria 
3.3.3 Preparation of cyanobacterial monocultures 95

$\begin{array}{lll}\text { 3.3.4 Isolation of cyanobacteria } & 95\end{array}$

$\begin{array}{lll}3.4 & \text { Preparation of axenic cyanobacteria cultures } & 95\end{array}$

3.5 Indication of Axenicity of prepared isolated monocultures of cyanobacteria

3.6 Extraction, identification and quantification of Microcystin

3.6.1 Extraction of cell bound Microcystins

3.6.2 Extraction of extracellular Microcystins in water

3.6.3 HPLC analysis of cyanotoxins

3.7 Quantification of MC-LR and Cylindrospermopsin by ELISA method

3.7.1 Sample preparation

3.7.2 Assay procedure for the Microcystin plate kit

3.7.3 Assay procedure for the Cylindrospermopsin plate kit

3.8 Molecular Screening of toxigenic cyanobacteria

3.8.1 Extraction of genomic DNA from cyanobacteria

3.8.2 DNA extraction with lysis buffer

3.8.3 DNA extraction using cetyl trimethyl ammonium bromide [CTAB / $\left(\mathrm{C}_{16} \mathrm{H}_{33}\right)$ $\mathrm{N}\left(\mathrm{CH}_{3}\right)_{3} \mathrm{Br}$ / hexa decyl trimethyl ammonium bromide]

3.8.4 Molecular screening of cyanobacteria for the presence of MC producing gene clusters 
$\begin{array}{lll}3.9 .1 & \text { Purification of PCR product } & 107\end{array}$

$\begin{array}{ll}3.9 .2 & \text { Sequencing PCR } \\ & 108\end{array}$

$\begin{array}{ll}\text { 3.9.3 Clean-up of sequencing PCR product } & 108\end{array}$

$\begin{array}{lll}3.9 .4 & \text { Analysis of sequencing data } & 109\end{array}$

$\begin{array}{ll}3.10 & \text { Artemia (Brine Shrimp) Bioassay } \\ & 110\end{array}$

3.11 In vitro experiments for the evaluation of the effect of cyanotoxins on $\begin{array}{lr}\text { Human renal cell lines } & 111\end{array}$

$\begin{array}{ll}3.11 .1 \text { Cell cultures and reagents } & 111\end{array}$

$\begin{array}{ll}3.11 .2 \text { Cell culture maintenance } & 111\end{array}$

$\begin{array}{ll}3.11 .3 \text { Cytotoxicity assays } & 112\end{array}$

3.11.4 Morphological observations using phase contrast microscopy $\quad 114$

3.11.5 Morphological observations using Fluorescence microscopy 115

$\begin{array}{ll}\text { 3.11.6 Gene expression analysis by RT-PCR } & 115\end{array}$

3.11.7 Measurement of caspase-3 and caspase-9 enzymatic activity 118

$\begin{array}{ll}3.12 & \text { Statistical analysis } \\ & 118\end{array}$

$\begin{array}{lr}\text { 4. Results } & 120\end{array}$

$\begin{array}{llr}4.1 & \text { Field studies } & 120\end{array}$

4.2 Water quality parameters, chlorophyll-a and cyanotoxins in water bodies

4.2.1 Principal Component Analysis: Temperature, $\mathrm{pH}, \mathrm{DO}$, Conductivity, Total nitrate, Total phosphate analysis 
4.3.2 Preparation of batch cultures for cyanobacteria isolation

4.7.2 Molecular screening of cyanobacteria for the presence of MC producing gene clusters

4.7.3 Optimization of annealing temperature

4.7.4 Optimization of $\mathrm{MgCl}_{2}$ volume

4.7.5 PCR analysis of environmental samples

4.8.1 Analysis of Sequencing Data

4.10 Cell culture based experiments for the evaluation of the effect of cyanotoxins on Human renal cell lines

4.10.1 Cytotoxicity assays

4.10.2 Preliminary cytotoxicity assessment of different cyanotoxins 
4.11 Morphological observations using Phase contrast and Fluorescence microscopy

4.11.1 Morphological changes exerted by MC-LR on HEK-293 and ACHN cells 151

4.11.2 Morphological changes exerted by cyanobacterial crude extract on HEK293 and ACHN cells

4.12 Morphological observations using Fluorescence microscopy

4.13 Gene expression analysis by RT-PCR

4.14 Measurement of caspase- 3 and caspase-9 enzymatic activity

5. Discussion

5.1 Conclusion

6. References

7. Appendices

7.1 APPENDIX I (List of Publications)

7.2 APPENDIX II (GIS maps for location of sampling and water qualities of reservoirs studied)

7.3 APPENDIX III (Solution Preparation)

7.4 APPENDIX IV (Analysis of chemical water quality parameters) 


\section{List of Figures}

Figure 2.1 Basic morphotypes of cyanobacteria

Figure 2.2 Biological activities of cyanobacterial compounds up to 1996.

Figure 2.3 Main types of cyanotoxins

Figure 2.4 Chemical structure of MC molecule with variable amino acid molecules in $\mathrm{X}$ and $\mathrm{Y}$ positions

Figure 2.5 Structure of Cylindrospermopsin molecule 42

Figure 2.6 Gene cluster for microcystin biosynthesis in M. aeruginosa. 53

Figure 2.7 Schematic representation of the biosynthetic assembly line of microcystin. 55

Figure 2.8 Presumed modular structure of the microcystin PKS 57

Figure 2.9 Structures and arrangement of the gene clusters for microcystin biosynthesis of (b) M. aeruginosa, (c) P. agardhii and (d) Anabaena sp......................................... 58

Figure 2.10 Evolutionary forces acting on microcystin synthetase gene clusters. 61

Figure 2.11 Different techniques used for cyanobacterial biodiversity assessments......66

Figure 2.12 Schematic diagram showing damage caused by MCs on Hepatocytes. 68

Figure 2.13 Schematic representation of MC-LR absorption, distribution, metabolization and excretion (ADME) processes. 71

Figure 2.14 Effects of MC-LR induced toxicity on a Kidney cell model. 72

Figure 2.15 A simplified scheme of the two main pathways, the extrinsic and the intrinsic pathway of apoptosis.

Figure 2.16 Mechanisms involved in genotoxicity induced by MCLR. 76

Figure 2.17 Locations of CKD prevalence in globe. 80

Figure 2.18 CKDu prevalence in Sri Lanka .81

Figure 3.1 Locations of reservoirs selected for the study .89

Figure 3.2 Preparation of dilution series for isolation of cyanobacteria .94

Figure 4.1 GIS map for the MC-LR contamination levels in reservoirs studied 124 
Figure 4.2 Results of PCA for water quality parameters and concentrations of MC-LR and CYL

Figure 4.3 Appearance of greenish colonies in liquid batch cultures (a) and in solid batch culture plates (b).

Figure 4.4 Succession of growth of cyanobacteria on solid BG11- agar culture medium

Figure 4.5 Preparation of isolated cultures from liquid and solid batch cultures.

Figure 4.6 Batch cultures of similar cyanobacteria inocula containing different concentrations of antibiotic

Figure 4.7 HPLC profiles of Pure MC-LR standard and methanolic extract of Beira Lake.

Figure 4.8 Optimization of annealing temperature for $m c y$ A gene using mcyAF47 and mcyAR19 primer pair.

Figure 4.9 Optimization of annealing temperature for $m c y$ B gene using FAA and RAA primer pair.

Figure 4.10 Optimization of annealing temperature for mcy $E$ gene using mcyE-F2 and MicmcyE primer pair.

Figure 4.11 Optimization of $\mathrm{MgCl}_{2}$ concentration for $m c y E$ gene using mcyE-F2 and MicmcyE primer pair.

Figure 4.12 Agarose gel profile for amplified mcy $A$ gene using c primer pair for cyanobacterial DNA from reservoirs sampled.

Figure 4.13 Agarose gel profile for amplified $m c y$ A gene using mcy AF47 and mcy AR19 primer pair for cyanobacterial DNA from reservoirs sampled.

Figure 4.14 Agarose gel profile for amplified $m c y$ B gene using FAA and RAA primer pair for cyanobacterial DNA from reservoirs sampled

Figure 4.15 Agarose gel profile for amplified $m c y$ B gene using FAA and RAA primer pair for cyanobacterial DNA from reservoirs sampled 138

Figure 4.16 Agarose gel profile for amplified $m c y B$ gene using FAA and RAA primer pair for cyanobacterial DNA from reservoirs sampled

Figure 4.17 Agarose gel profile for amplified mcy E gene using mcyE-F2 and MicmcyE-R8 primer pair for cyanobacterial DNA from reservoirs sampled. 
Figure 4.18 Agarose gel profile for amplified mcy E gene using mcyE-F2 and MicmcyE-R8 primer pair for cyanobacterial DNA from reservoirs sampled.....

Figure 4.19 Agarose gel profile for amplified mcy E gene using mcyE-F2 and MicmcyE-R8 primer pair for cyanobacterial DNA from reservoirs sampled......

Figure 4.20 Optimization of annealing temperature for 16S rRNA gene using 16S F and 16S R primer pair.

Figure 4.21 BLAST result for GK22 strain.

Figure 4.22 BLAST result for BE25 strain.

Figure 4.23 BLAST result for NW26 strain.

Figure 4.24 Minimum likelihood tree generated from mega 6 software for cyanobacterial strains isolated from reservoirs.

Figure 4.25 Hydrated cysts of Artemia salina prior to hatching [A] Dead naupli due to intoxication [B] Active naupli in negative control [C].

Figure 4.26 Fluctuation of mean percentage mortality of Artemia salina with different concentrations of the MC-LR/ crude extracts of cyanobacteria.

Figure 4.27 Fluctuation of $\mathrm{IC}_{50}$ values on Artemia salina with exposure time 148

Figure 4.28 Comparative dose dependent cytotoxicity of MC-LR on HEK-293 (A) and ACHN (B) cell lines

Figure 4.29 Viability of ACHN and HEK-293cells exposed to different concentrations of cyanobacterial crude extract for $24 \mathrm{~h}$ assessed by SRB assay [a] and MTT assay [b].

Figure 4.30 Morphological characteristics of HEK-293 cells observed under phase contrast microscope exposed to different concentrations of MC-LR for $24 \mathrm{~h}$.....

Figure 4.31 Morphological characteristics of ACHN cells observed under phase contrast microscope exposed to different concentrations of MC-LR for $24 \mathrm{~h}$ 153

Figure 4.32 Morphological characteristics of ACHN cells observed under phase contrast microscope exposed to different concentrations of cyanobacterial crude extract for $24 \mathrm{~h}$

Figure 4.33 Morphological characteristics of HEK-293 cells observed under phase contrast microscope exposed to different concentrations of cyanobacterial crude extract for $24 \mathrm{~h}$ 
Figure 4.34 Fluorescence microscopic observations of MC-LR treated and non-treated $\mathrm{ACHN}$ cells stained with $\mathrm{AO} / \mathrm{EB}$ at $24 \mathrm{~h}$ post incubation

Figure 4.35 Fluorescence microscopic observations of MC-LR treated and non-treated HEK-293 cells stained with $\mathrm{AO} / \mathrm{EB}$ at $24 \mathrm{~h}$ post incubation

Figure 4.36 Effects of MC-LR on mRNA expression of Bax, Survivin and p53 genes in ACHN and HEK-293 cells after $24 \mathrm{~h}$ post-incubation.

Figure 4.37 Expression of caspase-3 [a] and caspase-9 [b] in ACHN cells and HEK-293 cells exposed to different concentrations of MC-LR for $24 \mathrm{~h}$. 


\section{List of Tables}

Table 2.1 Cyanobacterial toxins and their representative producers and toxic effects ...39

Table 2.2 Properties, distribution and biosynthetic genes of cyanobacterial toxin

families 40

Table 2.3 Animal poisoning incidents due to cyanotoxins .............................................44

Table 2.4 Different methods employed for detection of cyanotoxins in the world .........48

Table $2.5 \mathrm{LD}_{50}$ values of different cyanobacterial toxins after mouse bio assays. ..........50

Table 2.6 Methods available for the removal of cyanotoxins .......................................8 83

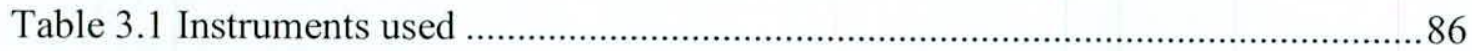

Table 3.2 Water quality parameters, respective abbreviations, units of measurement and methods of analysis.

Table 3.3 Reservoirs sampled for the present study with the districts and provinces they belong

Table 3.4 Linear gradient conditions used in HPLC analysis .98

Table 3.5 Details of the primer sets used for the PCR screening of cyanobacteria for mcy genes.

Table 3.6 Composition of PCR mixture.

Table 3.7 Annealing temperature gradients tested for each set of primer for the optimization of best annealing temperature

Table 3.8 Details of the primer set used for the sequencing analysis .

Table 3.9 Primer sequences for GAPDH, Bax, Survivin and p53 genes

Table 4.1 The user category, some physico-chemical and biological parameters of water bodies.

Table 4.2 Eigen analysis of the Correlation Matrix

Table 4.3 Scores for first four PCs.

Table 4.4 Qualitative and quantitative analysis of extracted DNA using two different methods by Bio-spec nano spectrophotometer ....

Table 4.5 Optimized annealing temperatures of primer sets used to screen mcy gene cluster. 
Table 4.6 Presence and absence of MC-LR producing genes; mcy A, mcy B and mcy E in water bodies

Table 4.7 Specific primers and optimized annealing temperatures for $16 \mathrm{~S}$ rRNA analysis

Table 4.8 IC $_{50}$ values of different types of cyanotoxins for HEK-293 and ACHN cell lines 


\section{List of Abbreviations}

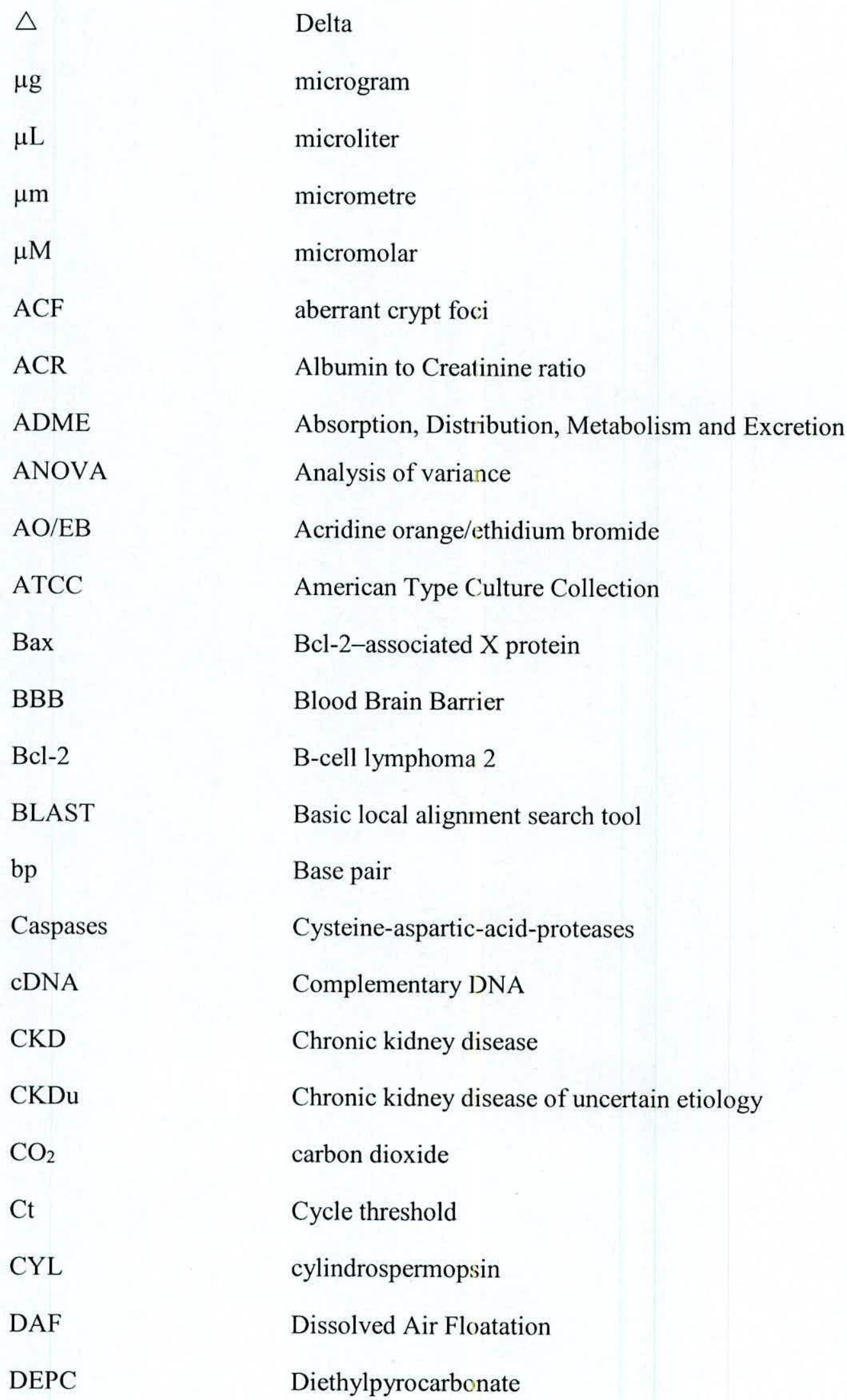


DMEM

DMSO

DNA

dNTP

DO

$\mathrm{EC}$

EDTA

eGFR

ELISA

EMEM

FA

FBS

g

$g$

GAPDH

$\mathrm{h}$

HAB

$\mathrm{Hb}$

$\mathrm{HCl}$

HPLC

IAP

IARC

IBMBB

$\mathrm{IC}_{50}$

ID
Dulbecco's modified eagle medium

Dimethyl sulfoxide

Deoxy ribo Nucleic Acid

Deoxy nucleotide triphosphate $(\mathrm{N}=\mathrm{A}, \mathrm{C}, \mathrm{T}, \mathrm{G})$

Dissolved Oxygen

Electrical Conductivity

Ethylene diamine tetra acetic acid

estimated Glomerular Filtration Ratio

Enzyme Linked Immuno Sorbant Assay

Eagles Minimum Essential Medium

fatty acid

Foetal bovine serum

gram

Gravitational force

Glyceraldehydes 3-phosphate dehydrogenase hour (Time)

harmful algal blooms

Haemoglobin

Hydrochloric acid

High Performance Liquid Chromatography

Inhibitors of Apoptosis

International agency for research on cancer

Institute of biochemistry, molecular biology and biotechnology

The half maximal inhibitory concentration

Identification 


\begin{tabular}{|c|c|}
\hline IP & intra peritoneal \\
\hline ITS & Internal Transcribed Spacer \\
\hline KDOQI & Kidney Disease Outcome Quality Initiative \\
\hline $\mathrm{kPa}$ & kilopascal \\
\hline LC & Liquid Chromatography \\
\hline M & Molar \\
\hline $\mathrm{MC}$ & microcystin \\
\hline MC-LR & microcystin LR \\
\hline $\mathrm{MgCl}_{2}$ & Magnesium chloride \\
\hline $\min$ & Minute (time) \\
\hline $\mathrm{mL}$ & milliliter \\
\hline $\mathrm{mM}$ & millimolar \\
\hline M-MLV & Moloney murine leukemia virus \\
\hline mRNA & Messenger ribonucleic acid \\
\hline MS & Mass Spectrometry \\
\hline MTT & $\begin{array}{l}\text { 3-(4, 5-dimethylthiazol-2yl) -2, 5-biphenyl tetrazolium } \\
\text { bromide }\end{array}$ \\
\hline $\mathrm{N}_{2}$ & nitrogen gas \\
\hline $\mathrm{NaCl}$ & Sodium Chloride \\
\hline $\mathrm{NaHCO}_{3}$ & Sodium bicarbonate \\
\hline NCBI & National Centre for Biotechnology Information \\
\hline NCP & North Central Procince \\
\hline ng & nanogram \\
\hline NGAL & Neutrophil gelatinase associated lipocalin \\
\hline NHMRC & National Health and Medical Research Council \\
\hline $\mathrm{NKF}$ & National Kidney Foundation \\
\hline
\end{tabular}


$\mathrm{nm}$

NMT

NOD

NRPS

NW

NWSDB

OATP

PBS

PC

PC

PCA

PCR

PDA

$\mathrm{pH}$

PKS

PP

qPCR

RFLP

RNA

RNasin

ROS

RPM

RT-PCR

S

SDS

SIR nanometer

$\mathrm{N}$-methyl transferase

nodularin

non-ribosomal peptide synthetase

North Western

National water supply and drainage board

organic anion transporting polypeptide

Phosphate buffered saline

phycocyanin

Principal Component

Principal Component Analysis

Polymerase chain reaction

Photo Diode Array

Power of hydrogen

polyketide synthetase

protein phosphatase

quantitative Polymerase chain reaction

Restriction Fragment Length Polymorphism

Ribonucleic acid

Ribonuclease Inhibitor

Reactive Oxygen Species

Revolutions per minute

Reverse transcriptase Polymerase chain reaction

second (time)

Sodium dodecyl sulphate

significant increased risk 


\begin{tabular}{ll} 
SPE & Solid Phase Extraction \\
SRB & Sulforhodamine B \\
TAE & Tris-acetate Ethylene diamine tetra acetic acid \\
TCA & Trichloroacetic acid \\
TDI & tolerable daily intake \\
TFA & Tri Fluoro Acetic acid \\
TIN & Tubular Injury \\
Tm & Melting temperature \\
TN & Total Nitrate \\
TP & Total Phosphate \\
TYG & Tryptone, Yeast extract, Glucose \\
U & Unit \\
USEPA & United States Environmental Protection Agency \\
UV & Ultra violet \\
V & Volt \\
WHO & world health organization \\
\hline
\end{tabular}




\section{ACKNOWLEDGIEMENT}

With immense pleasure I express my deep sense of gratitude and heartfelt thanks to my supervisor Professor Pathmalal Manage for his expert guidance, insightful criticisms, and continued encouragement throughout the study as well as in preparation of the thesis. His involvement in research has triggered and nourished my intellectual maturity that I will benefit from, for a long time to come. Without his support, patience and understanding on me, this study would not have been completed.

I wish to express my deep sense of gratitude to Prof. Kamani H. Tennekoon, Senior Professor of Molecular Life Sciences, Institute of Biochemistry, Molecular Biology and Biotechnology (IBMBB), University of Colombo for her valuable guidance, constructive suggestions and patient guidance in accomplishment of this work as a co supervisor. I would like to great thank Prof. Nissanka De Silva, my other Co-Supervisor for his valuable advice and motivation during the study.

It is a great privilege for me to thank Vidyajyothi, Emeritus Professor Eric H. Karunanayake, Founder Director of IBMBB and Former Chairman of National Research Council of Sri Lanka for his invaluable assistance and for providing me with this excellent opportunity of high-level research through providing NRC grant 11-034 to financially strengthen this work. I would like to express my acknowledgement to NRC for the financial support and the assistance given.

I am especially thankful to Dr. Sameera Samarakoon for his technical guidance, valuable advice and motivation throughout the duration of my study and for undertaking extensive editing during the writing of thesis as an immediate instructor for my Cell culture and Molecular biology experiments and the enthusiasm to complete this hard 
task as my husband. I am deeply indebted to my beloved parents, my sister and brother for their moral support and encouragement in my academic pursuits.

Especial thanks are also extended to academic staff as well as academic supporting staff of the Department of Zoology, University of Sri Jayewardenepura and IBMBB, University of Colombo for helping me in numerous ways.

Without the constant support of my colleagues Ms. Chanthirika, Ms. Sumaiya, Mr. Yohan, Ms. Indika, Ms. Yashodhara, Mr. Manoj, Ms. Nethu, Mr. Ravi and Mr. Thissa, I would not have been able to remain sane. Thank you so much for your generosity, kindness, willingness to help, and your smile and genuine friendship continued throughout the period of my research.

Finally, yet importantly, I would like to express my heartfelt thanks to my beloved daughters for their patience and providing me the moral support whenever I needed. With immense pleasure I express my deep sense of gratitude and heartfelt thanks to all who helped me even by a single word to encourage me to continue this task with all other commitments. 


\title{
Molecular Identification of Toxigenic Cyanobacteria and Effects of Cyanotoxins on Human Renal Cell Lines.
}

\section{M.A.P.C. Piyathilaka}

\begin{abstract}
Cyanobacterial toxins became widely recognized as a human health problem arising as a consequence of eutrophication. Present study was planned for the phylogenetic identification of toxic and non-toxic cyanobacteria in Sri Lankan water bodies to understand potential of toxigenicity for future water treatment solutions. Further, present work was planned to evaluate the cytotoxicity and possible apoptotic effects of cyanotoxins (microcystin LR/ MC-LR) and crude cyanobacteria toxin extracts on human embryonic kidney (HEK-293) and human kidney adenocarcinoma (ACHN) cell lines.
\end{abstract}

Forty water bodies from seven provinces were selected depending on the past history of cyanobacterial and cyanotoxin occurrence for the study to collect water and phytoplankton samples. Physico-chemical and some biological parameters of water were measured at the site itself and in the laboratory according to standard methods. Results reveled that most of the drinking water bodies were having acceptable water qualities. MC-LR and Cylindrospermopsin (CYL) contamination levels were assessed using ELISA method and HPLC and the highest MC-LR level was recorded in Beira Lake (2198.26 ppb).

Preparation of cyanobacterial batch and monocultures were achieved by testing number of culture media and BG11 culture medium was selected as the best. Extraction of 
genomic DNA from cultured cyanobacteria and whole cyanobacterial community in reservoirs was achieved by standard lysis buffer method. Presence of Microcystins (MCs) producing genes, mcy $A, m c y B$ and $m c y E$ in water was screened with PCR. The results of the specific PCR revealed that all the reservoirs having $m c y A, m c y B$ and $m c y$ E MC producing genes. Detectable level of MCs were not recorded in Borelesgamuwa Lake during the study period either by ELISA or HPLC. Interestingly presence of toxin producing genes in cyanobacteria in Borelesgamuwa Lake showed that there is a potential to produce MCs. Absence of MCs in Labugama, Kalatuwawa, Mahaweli River, Kantale podi wewa, Rathkinda and Minneriya reservoirs were further confirmed by PCR with negative results.

Phylogenetic analysis of some isolated cyanobacteria was achieved by sequencing $16 \mathrm{~S}$ rRNA gene region. One strain of Microcystis spp. was isolated from Beira Lake, Kurunegala Lake, Borelesgamuwa Lake, Giradurukotte reservoir and Nuwara wewa. Other than the strain isolated from Nuwara wewa, all strains were belonged to the same phylogenetic strain.

Toxicity of MC-LR and natural cyanotoxin extracts was assessed using Artemia (Brine shrimp) bio assay. Compared to toxicity of MC-LR, toxin extract prepared from Borelesgamuwa Lake had higher toxicity. Further, it was detected that decreasing tendency of $\mathrm{IC}_{50}$ values had a tendency to decrease along with the increasing incubation period for all extracts and any degradation of pure MC-LR was not detected during incubation period.

MTT (3-(4,5-dimethylthiazol-2-yl)-2,5-diphenyltetrazolium bromide) and SRB (Sulphorhodamine B) assays for cell viability revealed a significant decrease in cell 
viability in both cell lines after treatment with MC-LR at $50 \mu \mathrm{M}$ for $24 \mathrm{~h}(\mathrm{p}<0.001)$. Moreover, MC-LR treated ACHN and HEK-293 cells exhibited a marked dose dependent loss of confluence as judged by phase contrast microscopy. Similarly, fluorescence microscopic observations following Acridine Orange-Ethidium Bromide $(\mathrm{AO} / \mathrm{EB})$ staining confirmed that both cell types were undergoing apoptosis after treatment with MC-LR for $24 \mathrm{~h}$. Expression of three apoptosis related genes namely, Bax, Survivin and p53 was analyzed by quantitative RT-PCR analysis. Both Bax and p53 genes function as promoters of MC-LR mediated apoptosis in ACHN and HEK-293 cells. Survivin gene acts as a suppressor of apoptosis in lower MC-LR concentration (1 $\mu \mathrm{M})$ and the gene was up regulated at higher MC-LR concentration $(10 \mu \mathrm{M})$ tested $(\mathrm{p}<$ $0.001)$. A significant increase of caspase $3(\mathrm{p}<0.0001)$ and caspase $9(\mathrm{p}<0.0001)$ activity was detected in both cell lines after exposure to MC-LR for $24 \mathrm{~h}$ indicating that MC-LR induces cytotoxicity and a marked apoptosis in both ACHN and HEK-293 kidney cell lines. MC-LR treated ACHN and HEK-293 cells exhibited marked dose dependent cytotoxic and apoptotic effects in the present study contributing to elucidate the nephrotoxic effects of MC-LR on Human kidneys. 